\title{
An experience-based perspective on the relationship between indigenous and Western epistemic systems in research
}

\section{Dawn Adams}

The epistemic systems that inform indigenous and Western research methods are based on competing cultural truth claims about reality, including the ways of knowing, the nature of meaning, and the separation or participation of an observer. Ian Barbour's models of relationship between Western academic cultures with competing truth claims can be applied to the relationship between indigenous and Western research. Each of the four models of relationshipconflict, independence, dialogue, and integration-provides a meaningful context for understanding the statements and actions of Western scientists in response to indigenous research methods, and helps indigenous researchers recognise and defend against acculturation pressure. Dialogue and integration can create interstitial space for collaborative work between indigenous researchers and Western academic advisers, colleagues, journal editors, and grant-programme officers, though care must be taken that the collaborative process is not reframed back into a conflict model in which only Western epistemic processes are considered valid. 
This article is the product of more than 40 years' experience being a scientist who is Choctaw Indian. I came of age as an academic in mainstream university programs of geology, ecology, and evolutionary theory in which there were no other Indians. Even when I was working on my doctorate during the 1980s, resources for Indigenous science students were almost nonexistent. To put the time period in context, Haskell Indian Nations University didn't award its first 4-year college degrees until 1993, 4 years after I completed my $\mathrm{PhD}$ (Haskell Indian Nations University). The first major books about indigenous epistemology and science were also published after I finished graduate school: Vine Deloria, Jr.'s Red Earth, White Lies: Native Americans and the Myth of Scientific Fact, appeared in 1995, nine years after I'd joined the ranks of full-time faculty and a year after I landed my first National Science Foundation (NSF) grant; 'Spirit and Reason, a collection of Deloria's essays on epistemic issues, appeared in 1999, the year after I'd finally given up on academia after 12 years in the professoriate, and left it to found the nonprofit organisation Tapestry Institute; Linda Tuhiwai Smith's Decolonizing Methodologies: Research and Indigenous Peoples was also published in 1999, and Greg Cajete's Native Science: Natural Laws of Interdependence the year after, in 2000.

Figuring out how to integrate indigenous epistemic processes into my research in a programme of Western science felt like an extension of living as an Indian person in American culture: challenging and precarious, but achievable with prayer, ritual, and reflection. My father, Louis Allen Hill, Jr., a Choctaw civil engineering professor, had raised me to understand how to live this way, and was able to offer advice and counsel on many occasions. But even he was astonished by the depth of my dissertation adviser's contempt for Indigenous worldview. An increasing amount of my time and energy as a doctoral student and then faculty member was spent defending 
the validity of Indigenous worldview to Western academics who held my career in their hands as graduate advisers, journal editors, grant officers, faculty colleagues, and university administrators. I had to learn to articulate basic principles of indigenous knowledge and how they compare to Western science largely on my own, in the trenches, as a matter of survival.

I was encouraged, however, by knowing the Indian rights movement had laid conceptual groundwork for what I was trying to do. As a result, the American Association for the Advancement of Science had passed this formal resolution in 1975 (AAAS, 1975):

Be it resolved that the Council of the Association (a) formally recognise the contributions made by Native Americans in their own traditions of inquiry to the various fields of science, engineering, and medicine, and (b) encourage and support the development and growth of natural and social science programs in which traditional Native American approaches and contributions to science, engineering, and medicine are the subject of serious study and research (emphasis mine). ${ }^{2}$

I copied the resolution and showed it to my academic supervisors. It made no difference to most of them. I grew even more determined to find leverage Western scientists would have to respect.

I wound up discovering an international group of philosophers, physicists, chemists, and theologians who were meeting through the auspices of the Center for Theology and the Natural Sciences in Berkeley. These scholars were exploring the relationship between epistemology and research methods within Western culture itself. (I found out years later that Vine Deloria had participated in the group several years before I got there.) As I learnt how Western academics from different disciplines defend their methods of knowledge acquisition to one another, I realised there were "academically approved" tools I could appropriate to effectively defend Indigenous worldview 
to my Western colleagues. More important, I began to realise that more was at stake than whether I personally survived the acculturation process of graduate school and the faculty tenure process. I saw that research carried out within an indigenous epistemic system could bring positive change to science itself, as well as to the social structures and ecosystems it so heavily influences.

Twenty years of such work gave birth to the non-profit organisation the Tapestry Institute, which I founded in March of 1998. It informed the circle model of ways of knowing and learning that has visually expressed Tapestry's core mission since 1999 (Tapestry Institute, The circle, n.d.a), and led me to write nearly 60 individual webpages of basic educational text and a number of occasional papers on the organisation's website. It also led to my being asked to present seminars and talks to a number of institutions, ranging from MIT, to Princeton Theological Seminary, to the American Indigenous Research Association (AIRA).

This article is based on one of those presentations, a keynote I presented to the inaugural AIRA meeting in 2013, at the invitation of Dr Lori Lambert. It articulates the perspective I developed on the relationship between indigenous and Western epistemic systems in research, based on personal experience that predates the wonderful resources that have since become available to indigenous researchers. In that regard, it is no doubt naïve. But it's a perspective that helped me understand the context of my interactions with Western colleagues well enough to recognise a variety of subtle but significant acculturation pressures for what they were and successfully avoid them. On a few rewarding occasions, it even helped open the space for collaboration with Western colleagues such as the Co-PI on my first NSF grant.

In the first section of the article, I lay out three primary truth claims that inform Western and indigenous research methods. I 
explore each one and provide examples that create possible models for bridging Western and Indigenous worldviews in research situations. In the second section of the article I modify Ian Barbour's models of relationship between cultures with differing truth claims and apply it to Western and Indigenous worldviews, showing how each provides a meaningful context for recognising acts of acculturation. Finally, I explain how Barbour's modified model can help create a space for collaborative work with Western academic advisers, colleagues, journal editors, and grant-programme officers who don't understand what we're trying to do until we explain it in a way they can understand.

\section{Competing Western and indigenous truth claims relating to research methods}

Most indigenous persons have had the experience of saying something out of Indigenous worldview and being "corrected" by a person in Western worldview. For example, the indigenous person might say the land is alive, to which the non-indigenous person responds, scoffing: "That's stupid. Dirt and rock are inanimate." In such a case, the two people are actually making different truth claims about reality based on their cultural worldviews.

The concept of truth claims originated in the field of theology and has been applied to conflict resolution between Western academic fields as widely different as religion and science (Hick, 1963). ${ }^{3}$ Truth claims are paradigmatically based, so competing truth claims are not easily resolved. They are essential to understand, however, because this is usually the first type of acculturation pressure levelled against a person attempting to use indigenous epistemic systems in research. If a respectful space for dialogue cannot be created at this point, nothing further is possible.

On the other hand, if we can help the non-indigenous person see that what appears to them as an "obviously true" statement about 
reality is, in fact, an aspect of cultural worldview (e.g., a "truth claim" instead of "the truth"), we may open the conversation far enough to allow mutually respectful exploration of cultural assumptions, ideas, and processes. In ideal situations, this can help create what Māori researchers Fiona Cram and Hazel Phillips (2012) have called "interstitial space ... a middle ground whereby researchers can acknowledge their own worldviews and come together for fruitful transdisciplinary engagements" (p.36). And that is the goal of the strategies outlined in this article - to understand our own and our Western colleagues' paradigms of reality well enough that we can help them work with us to create interstitial space instead of insisting that we acculturate.

The Western epistemic system that informs mainstream academic research methods is based on three truth claims about reality (Table 1): that a) only material, fact-based, logically derived information is real; b) meaning is derived from facts by reason and can be reduced to its constituent facts; and c) humans are separated from everything else that exists, so all information comes from either entirely outside human beings or from entirely inside human beings. ${ }^{4}$ These truth claims constitute significant elements of Western cultural worldview as a whole, which is why they are key elements of academic research methods. It is important to note that all three truth claims exist within the paradigm of materialism, which is the belief that only matter is real. 


\begin{tabular}{|c|c|c|}
\hline & $\begin{array}{l}\text { Truth Claims About Reality } \\
\text { That Inform Western Research } \\
\text { Methods }\end{array}$ & $\begin{array}{l}\text { Truth Claims About Reality That } \\
\text { Inform Indigenous Research } \\
\text { Methods }\end{array}$ \\
\hline $\begin{array}{l}\text { Ways of Knowing } \\
\text { and Learning }\end{array}$ & $\begin{array}{l}\text { 1. Only one way of knowing and } \\
\text { learning about the natural world } \\
\text { is valid: that which produces } \\
\text { fact-based, logically derived } \\
\text { information. }\end{array}$ & $\begin{array}{l}\text { 1. Multiple ways of knowing and } \\
\text { learning about the natural world } \\
\text { are valid, and sources of information } \\
\text { can include such things as story, } \\
\text { dream, proprioception, intellect, logic, } \\
\text { spiritual insight, and intuition. }\end{array}$ \\
\hline $\begin{array}{l}\text { The Nature of } \\
\text { Meaning }\end{array}$ & $\begin{array}{l}\text { 2. Meaning is a derivative property, } \\
\text { wholly reducible to the fact-based } \\
\text { information in the system. Meaning } \\
\text { is constructed by human intellect } \\
\text { through logical processes of } \\
\text { reason. }\end{array}$ & $\begin{array}{l}\text { 2. Meaning is an emergent } \\
\text { phenomenon, arising from } \\
\text { integrating different ways of knowing } \\
\text { with processes of human perception } \\
\text { and sense-making. Meaning is an } \\
\text { element of Reality that is usually } \\
\text { imperfectly understood by human } \\
\text { beings. }\end{array}$ \\
\hline $\begin{array}{l}\text { Separation or } \\
\text { Participation }\end{array}$ & $\begin{array}{l}\text { 3. Information comes from } \\
\text { either wholly outside a human } \\
\text { being (modernism; objectivity) } \\
\text { or wholly inside a human being } \\
\text { (postmodernism; subjectivity) } \\
\text { because humans are separated } \\
\text { from the natural world. }\end{array}$ & $\begin{array}{l}\text { 3. Information arises from the } \\
\text { dance-like, participatory interaction } \\
\text { between humans and the natural } \\
\text { world of which we are an inextricable } \\
\text { part. }\end{array}$ \\
\hline
\end{tabular}

Table 1. Comparison of the truth claims about reality that inform Western academic research methods and indigenous research methods. There are other ways to represent or summarise the truth claims of Western and also indigenous epistemic systems relevant to research. This list is not meant to be definitive, but to be descriptive in a way that facilitates comparison, analysis, and understanding.

The indigenous epistemic system that informs indigenous academic research methods is based on three truth claims about reality that differ from those of Western worldview: a) there are many ways of learning and knowing about the world, of which material and logical fact-based information is but one type; b) meaning emerges from the synthesis of different kinds of information; and c) humans are connected to everything around them in ways that make learning a participatory act. These very different truth claims are possible because Indigenous worldview is not based in the paradigm of materialism. ${ }^{5}$ An indigenous scholar who can articulate and discuss the Western 
and indigenous truth claims that inform both types of research methods may help Western colleagues see that their own research methods are not ontologically "correct", but influenced by culture and worldview. This is the first step in opening a dialogue that can create interstitial space.

\section{Ways of knowing and learning}

Western and indigenous truth claims about the ways humans learn and know about the natural world can be compared using a model developed in 1999 by myself and colleague Joanne L. Belasco, Esq, for use in Tapestry Institute. It is based on the Sacred Circle common to many Native nations in North America. The four quarters of the Circle can be manifested as four very general types or ways of knowing and learning: intellectual, experiential, spiritual, and mythic (Figure 1). The directional association of each is meaningful rather than symbolic (Tapestry Institute, Ways of knowing, n.d.g).

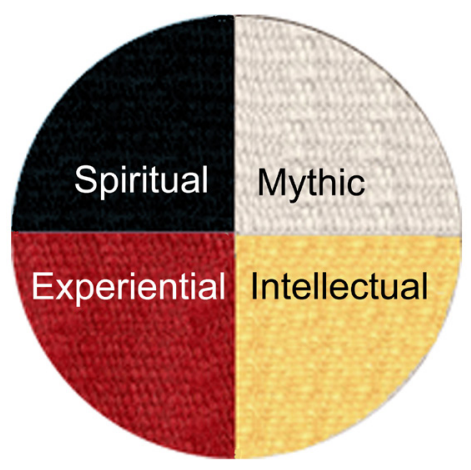

Figure 1. A typology of the different ways of knowing and learning based on the Sacred Circle common to many North American nations. Intellectual ways of learning and knowing are in the East; experiential ways are in the South; spiritual in the West; and mythic in the North. Directional associations with specific ways of learning and knowing are not intended to be merely symbolic. This model was developed by Dawn Hill Adams and Joanne L. Belasco for Tapestry Institute (http://tapestryinstitute.org/ways-of-knowing). 
In this typology, intellectual ways of learning and knowing include processes such as using logic, making measurements, and running statistical analyses (Tapestry Institute, Intellectual ways of learning and knowing, n.d.d.). Experiential ways of learning and knowing include intuition, proprioception, and physical experience (Tapestry Institute, Experiential ways of learning and knowing, n.d.b). Ritual, dream, and vision are three of the ways people learn through spiritual ways of knowing (Tapestry Institute, Spiritual ways of learning and knowing, n.d.f.). And appropriate types of story, art, music, and dance help us learn through mythic ways of knowing (Tapestry Institute, Mythic ways of learning and knowing, n.d.e). Of course, the different ways of knowing and learning are integrated for more complete understanding, a process referred to as integrated ways of knowing (Tapestry Institute, Integrated ways of learning and knowing, n.d.c). Integrated knowledge is represented by the wholeness of the Circle.

Western worldview only considers one of these ways of knowing, intellectual, to be valid (Figure 2a). ${ }^{6}$ So a lot of information that's available to human beings is simply not admissible in Western research, but is, instead, thrown away. Notice, however, that this does not mean the alternative to Western academia's worldview is one that disallows intellectual ways of knowing (Figure 2b), though that is the most common assumption of Western scholars who first encounter indigenous ways of knowing and learning in research. They do this because Western culture tends to be dualistic and often sees alternative views as either/or scenarios. But indigenous views of information acquisition are generally inclusive, not exclusive. 

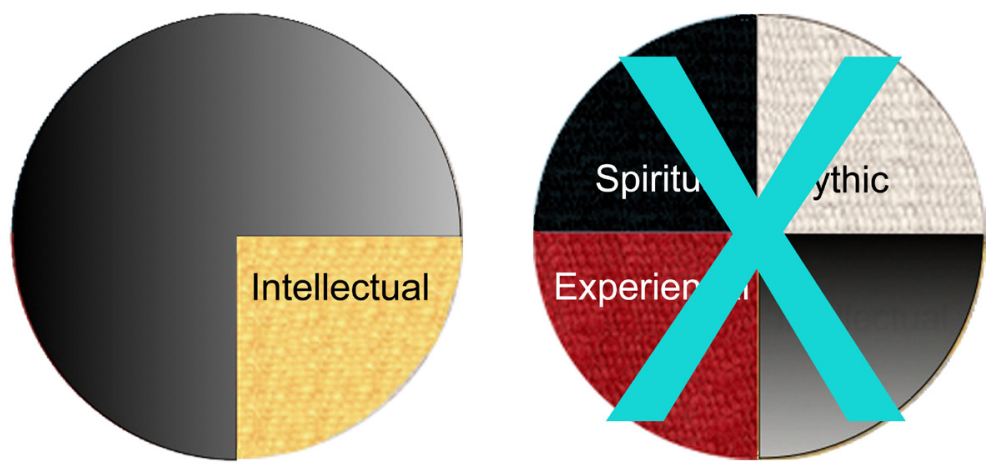

Figures $2 \mathrm{a}$ and $2 \mathrm{~b}$. Some cultures and individuals use only a subset of all the ways of knowing and learning available to human beings. (a) Western culture considers only intellectual ways of knowing to be valid. All the other ways of knowing are excluded from consideration. (b) Sometimes people in Western culture assume that indigenous people who acquire information through experiential, spiritual, and mythic ways of knowing must intentionally exclude intellectual ways of knowing. Their assumption is rooted in a deeply dualistic either/or view of reality that pervades Western culture, but it is misapplied in this case. Indigenous scholars should make sure their Western colleagues understand that inclusive use of all the different ways of learning and knowing, including intellectual, provides the richest and most complete integrated information.

Some Western scholars have a more inclusive view of information acquisition, and they face the same criticisms used to derail the research and careers of indigenous scholars. Familiarity with these scholars and the challenges they face in the Western academic community can help create awareness, understanding, and a bridge between Western and indigenous scholars with different truth claims about ways of knowing. Rachel Naomi Remen, MD, for example, is a prominent physician, author, and clinical professor in Family and Community Medicine at UC San Francisco who uses story as a way of knowing in her practice and teaching. Despite her successful track record, she is hard put to defend her use of story-based information. "[A]s a physician," she says (Remen, 2008), "I have been put down because I am a storyteller. In my profession, stories are seen as anecdotal evidence, a kind of a second-rate truth, a truth that has very limited 
value compared to data and research." However, she goes on to assert somewhat defiantly: "But stories have a lot more power than data." Many indigenous people would of course agree wholeheartedly.

More and more Western scholars are exploring the value and power of information learnt through a variety of ways of knowing, including proprioception, visual arts, and music. They navigate the violation of Western science's "intellectual ways of knowing only" truth claim largely by connecting other ways of knowing to the human neurological system and thence the brain-which is seen as the "seat" of intellectual ways of knowing (Adams, 2015a). The late neuroscientist Francisco Varela-Director of Research at CNRS, Paris and head of the Neurodynamics Unit at the Salpetrière Hospital, Parisestablished a line of research inquiry that's been particularly productive in documenting the ways human beings learn through multiple means of information acquisition (Varela, Lachaux, Rodriguez, \& Martinerie, 2001). As these lines of inquiry develop, they provide more and more support for the validity of indigenous ways of knowing, which makes it easier for us to successfully resist Western colleagues' pressure to acculturate and even to create interstitial space with those same people.

\section{The nature of meaning}

The second truth claim of Western culture that impacts indigenous research is about meaning. In Western science, the term meaning is roughly equivalent to conclusion. That is to say, meaning is seen as being derived from facts by a process of logical deduction. Therefore, meaning can be reduced to its constituent facts. An example of the Western view of meaning from neuroanatomical research about "the meaning of dreams" clarifies these points.

Neuroscience is, like most biology, extremely reductionist. That means neuroscientists assume that every single thing related to 
dreams must be the result of, and reducible to, biological processes alone. Since neuroscientists have observed that brain cells fire in certain patterns when a person is dreaming, they see the content, time of occurrence, and meaning of dreams as being wholly produced by those firing patterns. The cause of the patterns - the reason why particular neurons fire at particular times during sleep-is explained in various ways. The famous geneticist Francis Crick sees the firing pattern as a process that serves biological housekeeping functions such as discarding information acquired during waking hours so as not to clutter up the brain (Crick \& Mitchison, 1983). Since dreams can only have meaning that reduces to the processes that produce the firing (Western truth claim), Francis Crick feels it's important to neither recall nor contemplate dreams that are literally garbage in the process of disposal (F. Crick, personal communication, 1991).

Paul King (2013), a computational neuroscientist who specialises in the intersection between psychology and computer software, sees the neuronal firing patterns that produce dreams as simply random events. He says the reason dreams so often seem to have meaning anyway is that "one part of the brain [is] trying to make sense of the 'internal test patterns' generated by another part of the brain.” This is apophenia, the notion that the human brain is hard-wired to perceive patterns even when they aren't there. As evidence of this phenomenon in dreams, King cites a party game proposed by the philosopher Daniel Dennett in his 1991 book Consciousness Explained.

In this game, a person designated the Dream Guesser is asked to leave the room while someone describes a dream to the rest of the group. Then the Dream Guesser is supposed to return, ask yes/no questions about the dream of the other people, and use that information to reconstruct the dream's content and possible meaning. What the Dream Guesser doesn't know is that the people in the room have been instructed to answer his or her questions according to a 
nonsensical rule created on the spot: for example, to reply "yes" to questions that end in a vowel, and "no" to questions that end in a consonant. So now the Dream Guesser comes back into the room and asks questions that wind up having random and actually meaningless answers, but reconstructs a dream from those answers anyway. Then the players explain to the Guesser that the dream he or she has reconstructed is actually nonsense, merely a product of his or her own brain attempting to make sense of random or garbage information. This is why King (2013) pointed to this game as evidence that any meaning seen in dreams is just a product of our own brain processes.

It is important to point out that this conclusion is scientifically and logically fallacious. It is biologically normal for sensory and perception systems to perceive pattern and construct meaning from raw sensory data. Without this ability, sensory information would be literally meaningless. For instance, more than 50 years ago, Gibson \& Walk's 1960 study in the processing of meaning from sensory information demonstrated there's an age at which kittens realise that an abrupt change in the appearance of the surface beneath their pawsin the experiment it was the boundary between a table and the floor below-can signal a dangerous drop-off. When placed on a clear glass surface that extended well beyond the table boundary but still provided the visual cues of a drop-off under what was now a level surface, the kittens first explored the different area with a paw to interpret the visual information coming into their eyes, then learnt to interpret visual information alone to comprehend the literal lay of the land. Experiments in adult cats demonstrated which parts of the brain were responsible for this ability to construct meaning from perception. When those areas were surgically damaged, adult cats returned to fishing about with their paws to understand the ground, as if they were very young kittens. Yet no one would suggest that 
because a cat constructs meaning from sensory information, the drop-offs in their environment didn't really exist.

If Dennett's (1991) dream game proves that dream meaning is not real because it is only constructed from incoming sense data, then the same is true for all the meaningful information we acquire through our senses of sight, sound, scent, taste, and touch. If one were to argue that it's a matter of context and that the things we sense are real because they are in non-manipulated situations, then the same is true for dreams, and Dennett's dream game tells us nothing about the reality of dream structure and meaning in natural (rather than manipulated) situations. What the dream game really demonstrates is how far Western scientists will go to frame meaning as a solely derivative process.

In an Indigenous worldview, by comparison, meaning is an emergent phenomenon. Emergent means it is greater than the sum of its parts, whether those parts are information from different ways of knowing and learning or the engagement of human processes of pattern-recognition and meaning-construction. One of the more common examples of emergence is the picture in a European tapestry, which emerges from different colours of thread woven in a particular pattern. The picture can only be seen if you have the right perspective. It's not reducible to the individual threads, and if seen at too close a distance the pattern vanishes, and the larger picture with it.

Of course, there are multiple levels at which meaning can emerge, since the picture shown in a given tapestry can represent a story that has a meaning of its own: a historical event or myth, for instance. When symbols are incorporated into a woven object with clear intent and skilled ability by a weaver from an indigenous cultural tradition, even more meaning can emerge from the design. It can call places or beings into existence, right then and there, and engage the viewer as a participant in the story or event being depicted. 
This is true of many of the mythic ways of knowing and learning, of course, not merely woven ones. And it points to the fact that in Indigenous worldviews, meaning is often seen as something of an ultimate truth, one that exists whether humans see and understand it or not. So, meaning is not a construct, though humans may work to construct meaning from the information they have at hand. Rather, meaning is an element of reality itself. As such, the full and complete understanding of really important meanings lies beyond our reach, and our comprehension is always limited and tentative. New information can radically alter our understanding of meaning at any time. This awareness generates a deep humility about, and reverence for, meaning.

Kiowa author, N. Scott Momaday (1997), writes about the Barrier Canyon petroglyphs in a way that expresses this sense of meaning very well:

We do not know the story, but we see its enactment on the face of the earth, that it reaches from the beginning of time to the present to a destiny beyond time. We do not know what the story means, but far more importantly we know that it means, and that we are deeply involved in its meaning. The sacred is profoundly mysterious, and our belief is not less profound. (pp.130-131)

Momaday's eloquent articulation of the indigenous experience of meaning underscores, by contrast, Western culture's derivative truth claim about meaning being commensurate with a demonstrable or provable conclusion.

\section{Separation and participation}

The third and last truth claim of the epistemic system that informs Western cultural research methods is that every human is isolated, separated from absolutely everything else by the barrier of skin in which our sense organs are embedded. To most Western researchers, 
this means that valid information about the world can only exist outside an observer. This is generally the core of what's called modernism, and it's a salient feature of Western scientific research method. Postmodernism has recently flipped the separation paradigm to insist that valid information about the world arises inside an individual person, the perceptions and interpretations of that person being determined to a great extent by prior and ongoing social experience. Important consequences of this view include that all meaning is constructed by the perceiving individual and that individuals literally create their own experiences, values, and reality.

Of course, the concepts of "entirely outside a person" or "entirely inside a person" have no meaning in an Indigenous worldview, in which humans are seen as an integral part of the natural world. In Indigenous research methods, information is seen as arising through the interaction between a person and his or her environment. This type of information system has been referred to as relationship- or participation-based, and ceremony or ritual are considered vital elements of the system (Wilson, 2008; Cajete, 1999; Adams, 2016). This truth claim is probably the most difficult to bridge with Western colleagues, whose dedication to mainstream science's ethos of objectivity makes the notion of participatory observation highly uncomfortable. $^{8}$

\section{Relationships between cultures with conflicting truth claims}

Even within academia, Western culture's truth claims about reality create problems. Humanities scholars have a more difficult time making their experiences fit those claims than scientists do. In 1959, during the heyday of modernist scholarship, philosopher C.P. Snow began to refer to this as "The Two Cultures" problem, the two cultures being science and the humanities and the problem being that 
they had trouble getting along because one was constantly telling the other how to do things "correctly." This sounds familiar for a reason. The two cultures relationship between science and the humanities mirrors the relationship between Western and indigenous cultures.

In the 1960s, physicist and theologian Ian Barbour expanded C.P. Snow's model to explore the ways science and religion have handled the discomfort of the two cultures relationship since the Renaissance (Barbour, 1966). He identified four types of relationship between them: conflict, independence, dialogue, and integration (Figure 3). Barbour's model can be applied to the relationship between Western and indigenous research cultures and help us recognise the ways Western culture's truth claims about reality are brought to bear on indigenous scholars. It also helps us understand how we can try to create interstitial space with willing colleagues in Western academia.

\section{Conflict model of relationship}

In Barbour's conflict model, two cultures make conflicting claims about reality, with at least one party having the perception that only one of the claims can be logically true. Ideological war between groups with conflicting truth claims is the most dramatic outcome of the conflict relationship. When one culture dominates the other sociopolitically, the conflict model leads to paternalistic programs of education designed to acculturate people of the minority group into holding the "correct" truth claims and values of the dominant group. At an individual level, the conflict model leads individuals in the dominant sociopolitical group to engage in psychologically abusive crazymaking or gaslighting behaviours that manipulate members of the minority group into believing the dominant group's truth claims. ${ }^{9}$

Crazymaking behaviour consists of one person repeatedly denying the experiences and perceptions of another person. A perpetrator might say, "That didn't really happen," or "It doesn't actually hurt 


\section{Modified Version of Barbour's Typology of Two-Cultures Relationships \\ Conflict model of relationship}

- The two cultures are seen as making conflicting and mutually exclusive truth claims about reality, only one of which can be correct.

- This type of relationship results in overt conflict such as war, or in covert conflict such as acculturation.

\section{Independence model of relationship}

- The two cultures are seen as making truth claims about completely different and unrelated aspects of reality, using different methods to acquire understanding about different things.

- This type of relationship results in division of authority and expertise into non-overlapping spheres of influence.

\section{Dialogue model of relationship}

- The two cultures are seen as making apparently different truth claims about a single reality only because different processes have been used to investigate that reality.

- This type of relationship results in exploration of the ways human beings experience and know reality through epistemology and cognitive psychology.

\section{Integration model of relationship}

- The two cultures are seen as synergistically related, such that integrating their different truth claims leads to the emergence of a new understanding of reality that is greater than the sum of its parts.

- This type of relationship results in collaborative, creative relationships between different cultures

Figure 3. A version of lan Barbour's typology of the relationship between science and religion, modified by Adams. Barbour's model grew out of C.P. Snow's two-cultures work (1959) and can be applied to many two-cultures relationships, including that between Western and indigenous cultures. Though Barbour proposed the basic typology over 50 years ago (Barbour 1966), he continued to develop and refine it through a long and prolific career afterward. The typology has also been revised and expanded by other scholars. 
that bad." In the first example of conflicting Western and indigenous truth claims given in this article, the perpetrator says "Dirt and rock are inanimate" and that it's "stupid" for an indigenous person to think land is alive. Crazymaking statements of experience-denial are so relentless that the person subjected to this kind of psychological abuse begins to literally doubt his or her own memory, feelings, emotions, and reactions. They begin to feel they don't know what is true, or even real.

A person who is constantly told they don't know what they know, that they do not experience the things they experience, and that they do not really hear, see, or feel the things they are aware of hearing, seeing, and feeling eventually experiences anxiety disorder, depression, PTSD, and/or suicidal thought, and may engage in substance abuse as a coping mechanism. The only way out of the abuse is for the victim to gain a vantage point that allows her or him to clearly understand that other people see, hear, and feel the same things they do, that other people experience and perceive the same things they experience and perceive, and that the actions of the crazymaking abuser are elements of a power struggle about the nature of reality, not merely an act of correction or instruction.

Western culture is crazymaking to indigenous people because it denies our experience of reality. Because many people in the Western research community are in a conflict model of relationship, they assume that only Western truth claims about knowledge acquisition can be "right," so they deny the truth claims that inform indigenous research in ways that are psychologically abusive. When a thesis adviser tells an indigenous student to "grow up" and develop objectivity about a research subject because objectivity is "real instead of mumbo-jumbo," the adviser is using crazymaking as a strategy to "win" what s/he sees as a conflict between competing cultural truth claims about how information is acquired (Table 1). 
Repeated crazymaking behaviour is traumatic and often drives indigenous students and young faculty members out of the very system that wonders why it cannot keep indigenous people in the "STEM pipeline" (Adams, 2015b). One reason a community of indigenous researchers is so important is that it affirms the truth claims informing indigenous research methods and so provides a vantage point that helps students successfully resist the pressure of Western science to conform to standards it's defined as "acultural”an interesting claim given that the goal of crazymaking behaviour is acculturation. Acculturation is a strategy that speaks to the presence of the conflict model of differing cultural truth claims.

\section{Independence model of relationship}

In Barbour's independence model of relationship, Western and indigenous researchers are seen as talking about fundamentally different things and using their different methods to address non-overlapping issues of human existence. Many indigenous people who work in government or university research labs are in the independence model of cultural relationship. For example, an American Indian research geneticist once told me: "Of course it's all right to believe in Coyote, but it's important not to bring him into the lab." Although not bringing Coyote into the lab could certainly be a good strategy in terms of possible consequences-given the proclivities of Coyote in certain traditions - that's not what he meant. He meant he felt a Native scientist should drop culture at the door of the lab and pick it back up on the way home at night.

Independence is a model that's frequently encouraged by federal labs in Indian Country who have a number of Native employees. It permits these labs to increase their minority hiring statistics without changing the job requirements or practices of their field or bench technicians. The idea is that if the Native person in question wants 
to acquire information in an indigenous way, then she or he should work in a traditional tribal role-as a healer, for instance-rather than in a science lab. The two "jobs" and sets of truth claims and methods are seen as non-overlapping and concerned with wholly different goals. In the independence model of relationship, an indigenous person can engage in either one, but cannot import one set of truth claims into the other.

\section{Dialogue model of relationship}

The dialogue model of relationship between cultures with different truth claims sets aside differences and essentially says, "We're all working with good will and doing the best we can, so there must be some reason we keep coming up with different information when we look at the world." The focus, therefore, turns to how humans learn and know-the methods used, the kinds of questions that are asked, and the assumptions about reality that lead people to ask certain questions or look in particular places for answers. The dialogue model assumes that people get different results because they are asking different questions and going about things in different ways, so developing methods based in common epistemic and cognitive psychological ground will ideally produce views of reality with high levels of cross-cultural coherence. This is one of the places where interstitial space between indigenous and Western researchers can be created.

It sounds good on paper. But because epistemology and cognitive psychology are both academic disciplines based in Western culture, dialogue is still largely constrained by the Western truth claim that only fact-based, logically-derived information is real. So, dialogue is only possible when someone figures out how to translate the information provided by a non-intellectual way of knowing into empirical data. A study published in the prestigious journal Science, "Reading 
Literary Fiction Improves Theory of Mind" (Kidd and Castano, 2013) demonstrates what this kind of translation looks like in practice. It converts the benefits of reading literature, which is of course a mythic way of knowing, into quantifiable data. The authors do this by building on earlier work that defines the ability to understand the mental states of others as a skill called theory of mind, or ToM. They show that reading literary fiction improves test subjects' ToM scores and therefore makes them better able to understand other people.

Co-author David Comer Kidd perfectly articulates the value given to empirical data in the dialogue model of relationship (Boyce, 2013):

This study could be a first step toward a better understanding of how the arts influence how we think. We're having a lot of debates right now about the value of the arts, the value of the humanities. Municipalities are facing budget cuts and there are questions about why are we supporting these libraries. And one thing that's noticeably absent from a lot of these debates is empirical evidence.

It is clear that although the study's authors consider literature a valid way of knowing and learning and are therefore in a dialogue model of relationship, they are only able to do so because they have found a way for literature to produce the same type of empirical data that's acceptable in scientific research. Their work stands firmly within the Western culture truth claim that only intellectual ways of knowing provide valid information-even though they are dealing with a way of knowing (literature/story) that is inherently mythic.

This type of methodological bias can be a double-edged sword that very gratifyingly "proves" things we want to affirm but at the same time destroys other things that are important and precious. In 2001, when I was heavily engaged in NSF work, a programme offcer (PO) who was sympathetic to American Indians kept trying to 
get me to propose a project he desperately wanted to fund, that would analyse a certain American Indian nation's medical and ecological practices in order to "prove" they were valid. This PO was attempting to carry out the type of translation seen in the literature study just cited. I would not do the project, though Tapestry could certainly have used the grant money, because the PO's intentions to validate indigenous ways with science would have "officially" declared one subset of processes to be real-and, at the same time, invalidated every other method or process of the same large group of indigenous ways as not real (Figure 4). This is the problem with the hidden methodological constraints of the dialogue model of relationship, however promising it often sounds at first.

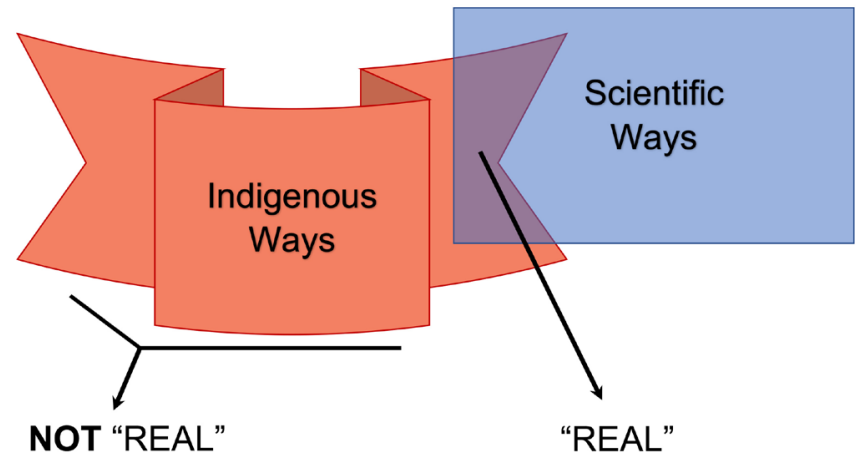

Figure 4. The dialogue model of relationship between Western science and indigenous ways is a double-edged sword. If Western research methods are used to evaluate indigenous practices, some may be "proven valid". But at the same time, practices that use non-intellectual ways of knowing, that address emergent-level meaning, or that engage humans in participatory learning fall outside the scope of science. Those practices wind up being "disproven" and declared officially not real. It is essential to remember that Western science is not the arbiter of what is real or not real. When its methods are applied to indigenous ways, they can only tell us which Indigenous ways use the same set of methods used by Western science.

An ancient Greek story tells us a lot about the way Western culture often engages in dialogue. Procrustes was a half-god, half-human being who waylaid travellers on the road to Athens and forced them 
to lie down in his iron bed. Notice the important symbolism of an iron bed, which is rigid and unyielding. Once travellers lay down on the bed, Procrustes made them fit it. If the person was too long and hung off the end of the bed, he whacked their legs off with an axe. If the person was too short and did not fill the bed, he put them on a rack and tore their joints apart to stretch them out appropriately. The people Procrustes met-who were merely passing by, minding their own business - literally had to fit his standard to survive. In the Greek story, a hero named Theseus eventually put Procrustes on his own bed and put an end to things. We seem to have no such hero available to us. What we have to do, instead, is watch out for that bed. Its name is assessment.

Every time we get grant funds to support our work and our communities, we have to explain how we will assess the outcome. In so doing, we enter a dialogue model of competing truth claims with the funding agency. The assessment we provide them must, somehow, yield empirical data-even if it's a non-parametric statistical test of coded narrative responses. But getting those responses and coding them and then throwing out every other type of information about our programme's results is a hidden Procrustean bed. Of course there is nothing at all wrong with including empirical data in our work. What is wrong is excluding every other type of information. It cuts off our legs at about the level of our hearts, and throws them away. Then we wonder why we're suffering.

\section{Integration model of relationship}

The last and rarest type of interaction Barbour identified between cultures with different truth claims is integration. Integration attempts to synthesise different ways of knowing (method) as well as information so that wholly new understandings can emerge that are not reducible to their component parts. Notice this type of relationship actually 
violates the first two truth claims of the Western research epistemic system we've described: it uses more than one way of knowing and it seeks emergent meaning that is not reducible to constituent facts. That's why this type of relationship is so rare.

In practice, most of the integrated models of relationship between science and religion that Barbour identified privilege one discipline or the other. However, process thought is a field of scholarship in philosophy and theology that seems to integrate disciplines and methods without undue weighting or privileging. And some scholars feel that the field of resilience ecology is a scientific discipline that also truly integrates different methods and kinds of information.

The formal AAAS resolution of 1975 cited earlier in this article (AAAS, 1975) clearly sets out an integrated model of relationship between Western and Indigenous science, specifically addressing epistemic processes of research (ways of knowing) as well as information (knowledge) itself. The resolution recognised contributions made "in [Native American peoples'] own traditions of inquiry," and then both encouraged and supported the "development and growth" of natural and social science programs using "traditional Native American approaches" to learning and knowing. This remarkable resolution created a breathtaking panorama of interstitial space for collaboration between Western and Indigenous science. And the attitude of methodological openness that found expression there found its way into science policy at a federal level throughout the next quarter-century. Publications of NSF programmes designed to enhance diversity in the sciences, engineering, and mathematics during those decades routinely stated that cultural diversity was essential because people of other cultures brought new and different methods, questions, and approaches to the field of scientific inquiry and research. These were seen as crucial because the desperate nature of the problems facing the world required innovative approaches. ${ }^{10}$ 
Between 1998 and 2003, however, discussions (of which I was a part) about the "rightness" of methodological Integration grew heated in a number of NSF committees and administrative bodies, as well as in AAAS. The notion that "science is science" and its methods are acultural—meaning simply ontologically "real"—regained prominence, along with the opinion that people who bring their own cultures' approaches, questions, assumptions, and accepted types of evidence into academia are, by definition, not practicing science. Eventually the integration model of relationship faded from national science policy documents of all kinds. At NSF today, diversity is discussed solely as a "human capital" issue that (a) brings indigenous (and other "under-represented") people into the sciences to satisfy a labour shortage caused by not enough White people wanting a career in science any more, and (b) makes sure that indigenous (and other "under-represented") communities and individuals truly appreciate the value and knowledge of science (NSF 2010, NSF 2012). It is discouraging to see the previous opportunities for integrated relationship reframed in a conflict or independence model rather than at least one of dialogue. This makes it even more important to consciously establish dialogue and possibly integration models of relationship with individual Western academic colleagues so we can, together, generate the interstitial space necessary for indigenous research and researchers to flourish.

\section{Conclusion}

In my experience, the most challenging part of being an indigenous research scientist is not figuring out how to apply indigenous ways of knowing and learning to a problem or question. The most difficult and potentially destructive issues arise in the collaborative landscape between indigenous researchers and the Western scientists 
and academics who are graduate advisers, faculty colleagues, university administrators, journal editors, and grant programme officers. Applying Ian Barbour's models of relationship between cultures with competing truth claims to indigenous and Western science has helped me recognise and understand the things my Western colleagues do and say in that landscape. It has allowed me to resist acculturation pressures of different kinds, including the very subtle and therefore exceptionally dangerous kinds of acculturation that attend the processes of assessment and evaluation-including studies designed to "empirically validate" specific indigenous ways that unintentionally condemn indigenous processes that can't be translated into an empirical system of knowledge acquisition.

It was discouraging to see the potential for genuine integrated relationship outlined in AAAS and NSF documents during the last quarter of the 20th century fade back into conflict model in the last 15 years. Yet I know from personal experience that even while those documents were being created and actively circulated, the interstitial space they created did not extend as a practice into departments of graduate study even at progressive institutions such as UC Berkeley. How astonishing, given these things, to see an exponential increase in the numbers of indigenous students pursuing graduate degrees in research and insisting on creating space for dialogue and integration with their committee members! The challenges they face in doing this come as no surprise, but their eventual success after success does. I honour the courage, perseverance, and tenacity of each and every one of them. It is my hope that sharing what I learnt when I once walked the road they walk now will help keep their hearts safe and their spirits strong throughout this arduous journey they make for the benefit of All. 


\section{Notes}

1 NSF Grant No. DUE-9254171. Design and implementation of a Bioliteracy Laboratory course to replace traditional introductory non-majors biology laboratories at colleges and universities. D. [Hill] Adams and D. Wivagg, co-PIs. This programme applied an Indigenous worldview to science education, which at that time closely paralleled trends in authentic, student-centred, activitybased learning in revised science education curricula. I presented a paper on the indigenous epistemic and pedagogical foundations of our grant project to the 1999 AISES national conference in Minneapolis, MN.

2 According to a number of different program officers and administrators who had been in AAAS and NSF during the 1970s and early 80s, and who were still in these organisations in the late 1990s and early 2000s when I spoke with them, Vine Deloria was personally responsible for the resolution and its specific wording.

3 Theologian Wolfhart Pannenberg, among others, applied the concept of competing truth claims to differences between academic disciplines such as theology and science rather than to differences between religions. This led to the idea that people from different academic "cultures" such as science and religion could find epistemically-based ways to resolve competing truth claims, which would then permit collaborative discourse.

4 There are other ways to represent the truth claims of Western (and also indigenous) epistemic systems relevant to research. This list is not meant to be definitive, but to be descriptive in a way that facilitates comparison, analysis, and understanding.

5 For a more thorough discussion of the materialism and matter/spirit dualism paradigms that underpin the epistemic truth claims informing Western research here, see Adams, Dawn Hill. (2016). In Service to the Land: Indigenous Research Methods in the Natural Sciences. Tapestry Institute Occasional Papers, 2(1b). http:// tapestryinstitute.org/occasional-papers/in-service-to-the-landindigenous-researchmethods-in-the-natural-sciences-vol-2-no-1b-october-2016

6 Because observations of all types are made through human senses-even instrumentation produces images that must be read with human eyes — philosophy of science devotes a great deal of attention to the issue of so-called "sense data" and the means by which such data are manipulated to remove the observer as a participant in the process of acquiring knowledge. Aspects of the so-called scientific method, such as large sample size, randomised sampling, and replicability, are methods intended to minimise the participatory element of collecting sense data and change "experiential learning" into "intellectual learning." 
7 This article addresses postmodernism only tangentially because Western scientific researchers and academics whose methods are based in Western science are, almost by definition, not postmodernists. So postmodernism has little impact on indigenous people attempting to use Indigenous methods in their research. Yet postmodernism clearly exists and manifests clear exceptions to certain generalisations I've made about Western culture as it manifests in research. So I mentioned it in passing to at least acknowledge the existence of exceptions, however little those exceptions resolve the problems faced by indigenous researchers working with academics grounded in Western research methods.

8 A review of basic sense-data literature and discussion of what this means about experiential learning can serve as a starting point for creating interstitial space with Western colleagues troubled by the notion of participatory learning. Great care must be used if quantum mechanics is used as a potential bridge to a participatory truth claim because its ideas have been misappropriated by postmodernists to validate the idea that all knowledge comes from within the individual — which is still in the Western separation truth claim.

9 The description of crazymaking behaviour provided in this article comes from personal communication with professionals in the American Academy of Experts in Traumatic Stress, of which I was a member during the early 1990s. The concept of crazymaking was used routinely in therapeutic practice at that time, though was not considered a term of clinical diagnosis. In the later 1990s, the term gaslighting-derived from the 1944 MGM film Gaslight-began to replace the term crazymaking in popular and therapeutic literature and in clinical practice. However, whereas gaslighting is frequently seen as intentional and malicious, crazymaking was generally seen as a more subconscious act, however abusive the outcome. Because of the distinction between intentional and subconscious behaviour, I am using the term crazymaking here rather than gaslighting. Although it's true that some of the reality-denying statements of people in the dominant culture are so arrogant as to have malicious impact, I am not prepared to assert these actions are conscious and intentional, rather than subconscious patterns of transferred abuse. For introductory information on gaslighting, see the Gaslighting entry on the website for OMICS International, at http://research. omicsgroup.org/index.php/Gaslighting. OMICS International publishes more than 700 open access journals of scientific research.

10 The rise of feminist and cultural studies during the last half of the twentieth century produced a growing body of literature on the ways that science has been shaped by the culture and gender of those who developed and practiced it, and this literature contributed to science's process of self-examination as it sought to 
find "innovative approaches" to fields ranging from immunology to quantum physics. Science (both research and education) opened itself to considerations of the ways in which the methods and practices of science have been deeply influenced by masculine gender norms, Christian cultural norms, political tenets of the European Enlightenment, and so on. As it did, it considered how scientific research and education might be carried out in different but equally powerful ways by persons outside the normative gender and cultural "types" to which most Western scientists have historically belonged. In these cases, just as with Indigenous science, true methodological integration was being pursued as a viable possibility in mainstream science from roughly 1970 until the early 2000 s.

\section{Bibliography}

AAAS. (1975). "AAAS: Native American Science and Technology" Resolution adopted by the AAAS Council, January 31, 1975. From "About AAAS: History and Archives.” Retrieved from http://archives.aaas.org/ docs/resolutions.php?doc_id=309

Adams, D. H. (2015a). Assessment as acculturation: Procrustes in the land between the mountain and the sea. Tapestry Institute Occasional Papers, 1(2). Retrieved from http://tapestryinstitute.org/occasional-papers/ assessment-as-acculturation-vol-1-no-2-may-2015/

Adams, D. H. (2015b). Of pipelines and rivers: science and indigenous ways. Tapestry Institute Occasional Papers, 1(1). Retrieved from http:// tapestryinstitute.org/occasional-papers/of-pipelines-and-rivers-science-andindigenous-ways-vol-1-no-1-january-2015

Adams, D. H. (2016.) In service to the land: Indigenous research methods in the natural sciences. Tapestry Institute Occasional Papers, 2(1b). Retrieved from http://tapestryinstitute.org/occasional-papers/in-service-to-thelandindigenous-research-methods-in-the-natural-sciences-vol-2-no-1boctober-2016

Barbour, I. (1966). Issues in science and religion. Englewood Cliffs, NJ: Prentice-Hall.

Boyce, N. G. (2013). Want to read others' thoughts? Try reading literary fiction. NPR, October 14, 2013. Retrieved from 
http://www.npr.org/blogs/health/2013/10/04/229190837/

want-to-read-others-thoughts-try-reading-literary-fiction

Cajete, G. (1999). Native science: Natural laws of interdependence. Santa Fe, NM: Clear Light Publishers.

Cram, F., \& Phillips, H. (2012). Claiming interstitial space for multicultural, transdisciplinary research through community-up values. International Journal of Critical Indigenous Studies, 5(2), 36.

Crick, F. \& Mitchison, G. (1983). The function of dream sleep. Nature, 304, $111-114$.

Gibson, E. J. \& Walk, R. D. (1960). The "visual cliff". Scientific American, 202, 64-71.

Haskell Indian Nations University. (n.d.). School history. Retrieved from http://www.haskell.edu/about/history.php

Hick, J. J. (1963). Philosophy of religion. Engelwood Cliffs, NJ: Prentice-Hall.

Kidd, D. C., \& Castano, E. (2013). Reading literary fiction improves theory of mind. Science, October 3, 2013. https://doi.org/10.1126/science.1239918

King, P. (2013). What is dreaming? Slate, October 3, 2013. Retrieved from http://www.slate.com/blogs/quora/2013/10/03/what_is_dreaming.html

Momaday, N. S. (1997). The man made of words: Essays, stories, and passages (pp. 130-131). New York, NY: St. Martin's Press.

NSF. (2010. Program solicitation, opportunities for enhancing diversity in the geosciences $(O E D G)$, Document Number NSF 10-599. Washington, DC: National Science Foundation.

NSF. (2012). Human capital strategic plan, NSF Document Number hcsp2012. Washington, DC: National Science Foundation.

Remen, R. N. (2008, June). The gift of story: The art of living every minute of your life. Paper presented in the UCSF Mini Medical School for the Public series, San Francisco, CA. University of California Television (UCTV) show ID 14533. Retrieved from https://www.youtube.com/ watch?v=Q1xBjIHEhtg. 
Snow, C.P. (1959). The two cultures and the scientific revolution. New York, NY: Cambridge University Press.

Tapestry Institute. (n.d.a). The circle. Retrieved from http://tapestryinstitute. org/the-circle

Tapestry Institute. (n.d.b). Experiential ways of learning and knowing.

Retrieved from: http://tapestryinstitute.org/ways-of-knowing/experiential

Tapestry Institute. (n.d.c). Integrated ways of learning and knowing. Retrieved from: http://tapestryinstitute.org/ways-of-knowing/integrated Tapestry Institute. (n.d.d). Intellectual ways of learning and knowing. Retrieved from: http://tapestryinstitute.org/ways-of-knowing/intellectual Tapestry Institute. (n.d.e). Mythic ways of learning and knowing. Retrieved from: http://tapestryinstitute.org/ways-of-knowing/mythic

Tapestry Institute. (n.d.f). Spiritual ways of learning and knowing. Retrieved from: http://tapestryinstitute.org/ways-of-knowing/spiritual

Tapestry Institute. (n.d.g). Ways of knowing. Retrieved from http:// tapestryinstitute.org/ways-of-knowing.

Varela, F., Lachaux, J.-P., Rodriguez, E., \& Martinerie, J. (2001. The brainweb: Phase synchronization and large-scale integration. Nature Reviews: Neuroscience, 2: 229-239.

Wilson, S. (2008). Research is ceremony: Indigenous research methods. Nova Scotia, Canada: Fernwood Publishing.

\section{The author}

Dawn Hill Adams, PhD (Choctaw) is founder and senior scientist of nonprofit organization Tapestry Institute. She holds a doctorate in vertebrate paleontology with emphases on biomechanics and evolutionary theory from the University of California, Berkeley. She's received five grants from the National Science Foundation and was a professor until 1998.

Email:dawn@tapestryinstitute.org 